\title{
Seroprevalence of Hepatitis B Virus (HBV) among Voluntary Healthy Blood Donors at Tellewonyan Memorial Hospital Voinjama, Lofa County, Liberia
}

\author{
Ezekiel Kanue Fardolo1,2*, Emmanuel Timothy Cooper ${ }^{2,3}$, Caroline Nyawira Wahome4, \\ Jean K. Kaly ${ }^{5}$, Junior S. Puiyoe ${ }^{5}$
}

${ }^{1}$ Department of Medical Laboratory Science, School of Medicine, Kenyatta University, Nairobi, Kenya

${ }^{2}$ Department of Medical Laboratory Science, Mother Patern College of Health Sciences, Stella Maris Polytechnic University, Monrovia, Liberia

${ }^{3}$ USAID Infectious Diseases Research, Monrovia, Liberia

${ }^{4}$ Department of Biochemistry, Microbiology and Biotechnology, Kenyatta University, Nairobi, Kenya

${ }^{5}$ Medical Department, Telewonyan Memorial Hospital, Lofa, Liberia

Email: *fardolo12e@gmail.com

How to cite this paper: Fardolo, E.K., Cooper, E.T., Wahome, C.N., Kaly, J.K. and Puiyoe, J.S. (2021) Seroprevalence of Hepatitis B Virus (HBV) among Voluntary Healthy Blood Donors at Tellewonyan Memorial Hospital Voinjama, Lofa County, Liberia. Journal of Biosciences and Medicines, 9, 113-119.

https://doi.org/10.4236/jbm.2021.98010

Received: June 12, 2021

Accepted: August 20, 2021

Published: August 23, 2021

Copyright $\odot 2021$ by author(s) and Scientific Research Publishing Inc. This work is licensed under the Creative Commons Attribution International License (CC BY 4.0).

http://creativecommons.org/licenses/by/4.0/

\section{(c) (i) Open Access}

\begin{abstract}
Background: The prevalence of transfusion associated hepatitis B virus (HBV) infection differs across different population geographically. Ascertaining the seroprevalence of HBV infection is vital to informing the way of precautionary and control strategies. This study sought to establish the seroprevalence of hepatitis B surface antigen (HBVsAg) among blood donors in Yelewonyan Memorial Hospital Lofa, Liberia. Methods: This was a retrospective study which involved reviewing of blood donation records for the year 2020 at Telewonyan Memorial Hospital in Lofa County. The data obtained from the records were analyzed. Data analysis was done using SPSS version 12 for windows. Results: A total of 584 voluntary blood donors were screened for donation in 2020. Out of 584, 554 (95.9\%) were males while the rest were females. Prevalence of 3.3\% was observed among blood donors in Telewonyan Memorial Hospital. There is a significant difference between gender and age with HBV seropositivity among blood donors. Conclusion: The findings of this study suggest that the study site is of low endemicity with HBV infection. Usually, males are more probably to be HBVsAg seropositive than their female's counterpart. Planning more extensive study and educational programs would help minimize the spread of HBV infection among the general population.
\end{abstract}




\section{Keywords}

Liberia, Blood Donors, Seropositivity, HBV Infection, Blood

Transfusion, Lofa

\section{Introduction}

Hepatitis is a tenderness of the liver caused mainly by a viral infection. Hepatitis $\mathrm{B}$ virus (HBV) and hepatitis $\mathrm{C}$ virus (HCV) infections are responsible for a significant percentage of liver diseases in Africa and the world. They account for liver diseases ranging from minor to chronic stage. HBV is the world tenth leading cause of death, and a significant number of chronic carriers can develop liver cirrhosis. Most than one million people died of HBV related liver disease every year [1]. An envelope, partial dsDNA virus infects the liver, resulting in hepatitis B infection [2].

$\mathrm{HBV}$ is very infectious and transmitted chiefly through blood, body fluid, and from mother to child [3]. A 7\% population of the world is living with HVB infection [4]. The incubation time of $\mathrm{HBV}$ is three months from exposure to the time of the onset of symptoms.

The World Health Organization (WHO) has estimated that in 2015, 257 million were living with chronic HBV infection (defined as HBVsAg positive) and 887000 deaths annually, the majority from cirrhosis and hepatocellular carcinoma (WHO, 2015); [5]. Hepatitis endemicity in the world has been classified into three broad regions; high, intermediate and low region. Sub-Saharan has been classed as having high endemicity, and portions of North Africa has also been middle (WHO, 2011) [6].

Usually, a high prevalence of chronic HBV is $\geq 8 \%, 2 \%-8 \%$ as intermediate and low $<2 \%$. The prevalence of HBV differed geographically. High endemicity (that is $\geq 8 \%$ of the population are infected) of HBV is Sub-Saharan Africa (SSA) and the main cause of hepatocellular carcinoma [7] [8]. Some research had reported that $44 \%$ of cirrhosis and $47 \%$ of hepatocellular carcinoma cases in SSA are caused by HBV.

In developing nations, unsafe blood is still a main issue maybe due to the spread of viruses via blood and blood products creating serious public health concern [2]. The seroprevalence of HBV among blood donors in West Africa rangs from $3 \%$ to $22 \%$ [9] [10].

Liberia prevalence rate of chronic HBV stands at $10 \%$ and $519 \mathrm{HBV}$ related death according to the global hepatitis B virus report on Liberia (Liberia 2019). The study conducted by Shobayo et al. reported the prevalence of HBV $45.2 \%$ among adults' patients attending the Seven Day Adventist Cooper Hospital, Montserrado County [11]. However, the prevalence of HBV among blood donors in Tellewonyan Memorial hospital (TMH) remains unknown. This study 
sought to determine the prevalence and demographic factors associated with HBV positivity among blood donors in Tellewonyan Memorial hospital voinjamal, Lofa county Liberia.

\section{Significance of the Study}

This study is geared at establishing the seroprevalence and demographic association of HBV positivity among healthy blood donors in Tellewonyan Memorial Hospital, Voinjama, Lofa County. The results from this research will provide information on HBV infection in healthy blood donors. The findings will also help policymakers on the possible interventions to the prevention of HBV infection.

\section{Study Limitation}

The study did not consider Molecular detection, serological marker and liver enzymes of the affected blood donors. Therefore, the study was unable to establish a correlation between clinical conditions and HBV positivity. Secondly, the study did do not follow and monitor the disease progression of the affected blood donors.

\section{Methodology}

\subsection{Study Site}

The study was carried out at the Tellewonyan Memorial Hospital (TMH), which is located in Voinjama, Lofa County, Liberia.

\subsection{Study Design and Study Site}

The study was a retrospective study, carried out in Telewonyan Memorial Hospital Laboratory among blood donors January to December 2020 for the determination of HBV infection and demographic association of HBV positivity among the study population. Telewonyan Memorial Hospital is the referral hospital in Lofa County. It is situated at the capital of County.

\section{Inclusion and Exclusion Criteria}

The study included blood donors who met the donation criteria for donation of blood prescribed by the National blood Safety and excluded potential donors who did not meet the criteria.

\subsection{Targeted Population}

The study targeted 584 donors who donated at TMH blood bank during the period under review (January to December 2020). All donors were tested for transfusion transmissible infections such as HBV, HCV, HIV and syphilis in accordance with Liberia Blood Transfusion Services procedure before donation. The test strip for HBV used was immunoassay for surface antigen determination for HBV. 


\subsection{Laboratory Procedures}

\subsubsection{Collection of Blood}

Venous blood specimen was collected from blood donor who attended the blood bank. The whole blood was obtained; allowed to clot and spin at 3500 revolution per minute (rpm) for 2 minutes at room temperature. The serum was stored at $-20^{\circ} \mathrm{C}$ for further procedure. The blood was tested for HBV surface antigen, anti-HCV and anti-syphilis respectively.

\subsubsection{Procedure for Blood Testing}

One step hepatitis B surface antigen test strip (Shandong Highplus Biotech Co., Ltd. Shandong, China) was used for donor's serum screening. The serum was brought to room temperature before the testing procedure. It was tested for the presence of HBVsAg using the strip. The test has the sensitivity and specificity of $98 \%$ and $99 \%$ respectively. A positive result means the presence of the virus infection and negative also absence of virus.

\subsection{Data Analysis}

The data obtained from this study was entered into Microsoft Excel spread sheet for cleaning and exported to SPSS version 20 for windows. Socio-demographic data was analyzed using SPSS version 20 and used to generate frequency tables while bivariate logistic regression was used to determine the association between a socio-demographic factor and HBV seropositivity. Categorical variables (HBV positive and negative cases) were compared using Chi-square.

\subsection{Ethical Consideration}

The permission to conduct this study was obtained from the management of Tellewonyan Memorial Hospital. To maintain confidentiality, all information gathered from the screening file were coded and kept out of reach of unauthorized persons and hence the Ethical committee of the school of Health sciences ruled that no formal approval was required.

\section{Results}

A total of 584 blood donors were tested in 2020 for donation. Out of the 584 donors, 554 (94.9\%) were males and the rest were females (Table 1).

Table 1. Distribution of blood donors by gender, Telewonyan memorial hospital 2020.

\begin{tabular}{ccc}
\hline Gender Distribution & Frequency & Percentage (\%) \\
\hline Female & 30 & 5.1 \\
Male & 554 & 94.9 \\
Total & 584 & 100.0 \\
SE of Mean & & 0.01 \\
Standard Deviation & & 0.22
\end{tabular}




\subsection{Distribution of Blood Donors by Age}

The age of the blood donors was stratified into three age groups, $<20,20$ to 39 and $\geq 40$ respectively. Majority 550/584 (94.2\%) were between 20 to 39 years (Table 2).

\subsection{Seroprevalence of HBV among Blood Donors in Telewonyan Memorial Hospital (TMH)}

Out of the 584 voluntary blood donors in TMH, 19/584 (3.3\%) were seropositive to anti-HBVsAg (Table 3).

\subsection{Seroprevalence of HBV among Blood Donors by Socio-Demographic Features}

Out of the seropositive donors, 16 (84.2\%) were males and the rest were females. There was statistically significant difference with HBV seropositive and gender $(\mathrm{P}=0.03)$. When it comes to age, $20-39$ years age group has all the seropositive donors. There was significant difference with HBV seropositivity and age as well $(\mathrm{P}=0.01)($ Table 4$)$.

Table 2. Age distribution of the blood donors.

\begin{tabular}{ccc}
\hline Age Distribution & Frequency & Percentage (\%) \\
\hline 20 & 1 & 0.2 \\
$20-39$ & 550 & 94.2 \\
$\geq 40$ & 33 & 5.7 \\
Total & 584 & 100.0 \\
SE of Mean & & 0.01 \\
Standard Deviation & & 0.24 \\
\hline
\end{tabular}

Table 3. General seropositivity of the study population.

\begin{tabular}{ccc}
\hline General seropositivity & Frequency & Percentage (\%) \\
\hline Positive & 19 & 3.3 \\
Negative & 565 & 96.7 \\
Total & 584 & 100.0 \\
SE of Mean & & 0.01 \\
Standard Deviation & & 0.18 \\
\hline
\end{tabular}

Table 4. Seropositivity rates distributions among donors based on socio-demographic features.

\begin{tabular}{|c|c|c|c|c|c|c|}
\hline \multirow{2}{*}{$\begin{array}{c}\text { Socio-demographic } \\
\text { features }\end{array}$} & \multicolumn{5}{|c|}{ Seropositivity } & \multirow[b]{2}{*}{ P-value } \\
\hline & Categories & $\begin{array}{l}\text { Positive } \\
(n=19)\end{array}$ & $\begin{array}{c}\text { Percentage } \\
(\%)\end{array}$ & $\begin{array}{l}\text { Negative } \\
(n=565)\end{array}$ & $\begin{array}{c}\text { Percentage } \\
(\%)\end{array}$ & \\
\hline \multirow[t]{3}{*}{ Age Group } & $<20$ & 0 & 0.0 & 1 & 0.2 & 0.01 \\
\hline & $20-39$ & 19 & 100 & 531 & 93.9 & \\
\hline & $\geq 40$ & 0 & 0.0 & 33 & 5.8 & \\
\hline \multirow[t]{2}{*}{ Sex } & Female & 3 & 15.8 & 27 & 4.8 & 0.03 \\
\hline & Male & 16 & 84.2 & 538 & 95.2 & \\
\hline
\end{tabular}

Significance $\mathrm{P}<0.05$. 


\section{Discussion}

The transfusion of blood is an essential portion of healthcare delivery. Millions of lives are being saved through this protocol each year worldwide [3]. In Liberia, numerous people visit various hospitals blood banks and other blood donation centers around the country to donate to their loved ones who need blood to survive. This research showed that the majority of donors were males and were aged between 20 to 39 years. This finding is similar to the one observed from Ghana [3] observed that tendencies of male bias in blood donation are normal character similar occurrence among blood donation in sub-region. However, the reason for this occurrence may not be interfering directly with this research, it is said that certain beliefs and cultures may have a major role [11].

The seroprevalence of HBV infection examined among blood donors in this study was 3.3\% (19/584) and described as intermediate endemicity. This result is by the region HBV seroprevalence (3\% - 22\%). The seroprevalence is low than the one observed by Shobayo et al. among patients (45.24\%) at Seven Day Adventists Cooper Hospital in Monrovia Montserrado [9]. This study observed the highest seroprevalence (100\%) of HBV among blood donors between 20 - 39 years and none of the donors less than 20 years was tested positive to HBsAg. It is good to note that $94.2 \%$ of the donors were between 20 - 39 years old. This finding contradicted one observed in Monrovia.

\section{Conclusion}

This study has highlighted the burden of HBV infection in Voinjama, Liberia. The results imply that, however, the seroprevalence of HVB among blood is low as compared with other studies in Liberia; it remains within the high endemicity, the highest seroprevalence was observed among males and age between 20 and 39 years. Broader screening and vaccination campaigns within the diverse population, as well as educational programs on the risks and importance of immunization, should be undertaken to minimize the spread of HBV infection. A clear understanding of HBV seroprevalence infection in Lofa may be studied in the general population.

\section{Conflicts of Interest}

The authors declare no conflicts of interest regarding the publication of this paper.

\section{References}

[1] Sandhu, H.S., Roesel, S., Sharifuzzaman, M., Chunsuttiwat, S. and Tohme, R.A. (2020) Progress toward Hepatitis B Control-South-East Asia Region, 2016-2019. Morbidity and Mortality Weekly Report, 69, 988-992. https://doi.org/10.15585/mmwr.mm6930a2

[2] Gerelsaikhan, T., Tavis, J.E. and Bruss, V. (1996) Hepatitis B Virus Nucleocapsid Envelopment Does Not Occur without Genomic DNA Synthesis. Journal of Virology, 70, 4269-4274. https://doi.org/10.1128/jvi.70.7.4269-4274.1996 
[3] Li, M., Zu, J., Shen, M., Zhuang, G., Chen, S., Wang, F., et al. (2021). Evaluating the Independent Influence of Sexual Transmission on HBV Infection in China: A Modeling Study. BMC Public Health, 21, Article No. 388. https://doi.org/10.1186/s12889-021-10408-5

[4] Brener, L., Cama, E., Broady, T., Hopwood, M. and Treloar, C. (2021) Comparing Australian Health Worker and Student Attitudes and Concerns about Providing Care to People Living with Hepatitis B. Health Promotion Journal of Australia, 59, 249-6750. https://doi.org/10.1002/hpja.475

[5] Somi, M.H., Khayatzadeh, S., Nalbandy, M., Naghashi, S. and Nikniaz, Z. (2020) Estimating the Incidence Rate of Hepatitis B and C in East Azerbaijan, Islamic Republic of Iran. Eastern Mediterranean Health Journal, 26, 803-809.

https://doi.org/10.26719/emhj.19.077

[6] Walter, S.D., Eliasziw, M. and Donner, A. (1998) Sample Size and Optimal Designs for Reliability Studies. Statistics in Medicine, 17, 101-110.

https://doi.org/10.1002/(SICI)1097-0258(19980115)17:1<101::AID-SIM727>3.0.CO; $\underline{2-\mathrm{E}}$

[7] Kuniholm, M.H., Lesi, O.A., Mendy, M., Akano, A.O., Sam, O., Hall, A.J., et al. (2008) Aflatoxin Exposure and Viral Hepatitis in the Etiology of Liver Cirrhosis in the Gambia, West Africa. Environmental Health Perspectives, 116, 1553-1557. https://doi.org/10.1289/ehp.11661

[8] Osei, E., Lokpo, S.Y. and Agboli, E. (2017) Sero-Prevalence of Hepatitis B Infection among Blood Donors in a Secondary Care Hospital, Ghana (2014): A Retrospective Analysis. BMC Research Notes, 10, 1-5. https://doi.org/10.1186/s13104-017-2733-3

[9] Papastergiou, V., Lombardi, R., MacDonald, D. and Tsochatzis, E.A. (2015) Global Epidemiology of Hepatitis B Virus (HBV) Infection. Current Hepatology Reports, 14, 171-178. https://doi.org/10.1007/s11901-015-0269-3

[10] Yip, T.C.F. and Wong, G.L.H. (2019) Current Knowledge of Occult Hepatitis B Infection and Clinical Implications. In: Seminars in Liver Disease, Thieme Medical Publishers, Vol. 39, 249-260.

[11] Shobayo, B.I., Mawolo, J. and Chea, S.K.P. (2021) Prevalence and Risk Factors of Hepatitis B Infection in Patients Attended at the SDA Cooper Hospital, Sinkor, Liberia. Life Science Journal, 18, No. 2. 